\title{
THE ESA CLIMATE CHANGE INITIATIVE Satellite Data Records for Essential Climate Variables
}

by R. Hollmann, C. J. Merchant, R. Saunders, C. Downy, M. Buchwitz, A. Cazenave, E. Chuvieco, P. Defourny, G. de Leeuw, R. Forsberg, T. Holzer-Popp, F. Paul, S. Sandven, S. Sathyendranath, M. van Roozendael, and W. Wagner

The ESA's Climate Change Initiative is reprocessing and reassessing over 40 years of multi-sensor satellite records to generate consistent, traceable, long-term datasets of "essential climate variables" for the climate modeling and research communities.

S ustained observations from satellites contribute vital knowledge to our understanding of Earth's climate and how it is changing-one of the major challenges of the twenty-first century. Satellites observe on a global scale, which makes them useful for both the monitoring and modeling of climate and hence for improving the prediction and attribution of climate change. A major challenge in climate research is to move beyond single variable estimates of climate change to analyze and close the budgets of the energy, water, and carbon cycles characterizing our climate system (e.g., Trenberth et al. 2013).

AFFILIATIONS: HOLLMANN-Deutscher Wetterdienst (DWD), Offenbach, Germany; MERCHANT*_-University of Edinburgh, Edinburgh, United Kingdom; SAUNDERS-Met Office, Exeter, United Kingdom; DownY-European Space Agency, Harwell, United Kingdom; BuCHWITZ-University of Bremen, Bremen, Germany; Cazenave-Centre National d'Etudes Spatiales, Toulouse, France; CHUVIECO-University of Alcalá, Alcalá de Henares, Spain; Defourny - Earth and Life Institute, Université Catholique de Louvain, Louvain-la-Neuve, Belgium; DE LeEUW—Finnish Meteorological Institute, and Department of Physics, University of Helsinki, Helsinki, Finland; FORSBERG—National Space Institute, Technical University of Denmark, Lyngby, Denmark; HolzerPopp-German Aerospace Center (DLR), Wessling, Germany; PAUL-University of Zurich, Zurich, Switzerland; SANDVEN-Nansen Environmental and Remote Sensing Center, Bergen, Norway;
The Global Climate Observing System (GCOS) has set out requirements for satellite data to meet the needs of climate science, designating key variables that are currently feasible for observation and important to the United Nations Framework Convention on Climate Change (UNFCCC) as "essential climate variables” (ECVs) (GCOS 2011). The specifications given by GCOS for ECV data products are designed to provide information to characterize the state of the global climate system and enable long-term climate monitoring. This often requires data at longer temporal scales (such as weekly or monthly), but

SATHYENDRANATH-Plymouth Marine Laboratory, Plymouth, United Kingdom; van Roozendael-Aeronomy, Brussels, Belgium; WAGNER - Vienna University of Technology, Vienna, Austria * CURRENT AFFILIATION: University of Reading, Reading, United Kingdom CORRESPONDING AUTHOR: Rainer Hollmann, Deutscher Wetterdienst (DWD), Frankfurterstr. 135, 63067, Offenbach, Germany

E-mail: rainer.hollmann@dwd.de

The abstract for this article can be found in this issue, following the table of contents.

DOI:10.I175/BAMS-D-II-00254.I

In final form 12 December 2012

(C)2013 American Meteorological Society 
ECV data products are also used to validate model processes, for which data on hourly time scales are sometimes needed. Therefore, the ECV specifications may in some cases be a compromise. Where different instruments contribute observations toward an ECV, their products must be made consistent. Stringent requirements are also set by GCOS for quantifying uncertainties in ECVs.

In response, the European Space Agency (ESA) has launched the Climate Change Initiative (CCI) to provide satellite-based climate data records (CDRs) that meet the challenging requirements of the climate community (GCOS 2011). The aim is to realize the full potential of the long-term Earth observation (EO) archives that both ESA and third parties have established. This includes aspects of producing a CDR: data acquisition, calibration, algorithm development, validation, maintenance, and provision of the data to the climate research community.

The CCI is consistent with several international efforts targeting the generation of satellite derived climate data records. The Climate Data Record Program from the National Oceanic and Atmospheric Administration (NOAA; www.ncdc.noaa.gov/cdr/) aims to "develop and implement a robust, sustainable, and scientifically defensible approach to producing and preserving climate records from satellite data." The European Organisation for the Exploitation of Meteorological Satellites (EUMETSAT) also aims to provide certain climate data records in a sustained mode both within its own operational facility and its Climate Monitoring Satellite Application Facility (Schulz et al. 2009). Taking into account that the accuracy of the derived datasets critically depends on the availability of high quality satellite data, the Global Space-based Inter-Calibration System (Goldberg 2007) is being implemented to better characterize the intersatellite biases of the "level 1" data (i.e., calibrated and geolocated measurements of radiances, etc., prior to inference of geophysical variables). CCI uses the most recent and corrected level-1 datasets. Highlevel coordination of several global CDR activities is ensured through the World Meteorological Organization (WMO) Sustained, Coordinated Processing of Environmental Satellite Data for Climate Monitoring (SCOPE-CM), GCOS, and the Committee on Earth Observation Satellites (CEOS) working group on climate. The CCI program already works directly with GCOS and the World Climate Research Programme (WCRP) through their role in advising and assessing the program. In response, the CCI projects contribute through discussions, through directed feedback, or via the new ECV datasets to these programs.
Previous CDR development efforts, such as the satellite tropospheric temperature record (e.g., Mears and Wentz 2005, 2009; Christy et al. 2000), led to the conclusion that it is crucial to have a transparent, traceable, and sustainable process in terms of scientific algorithm development and also for the generation of the dataset itself. A thorough analysis of requirements and proper quantification of uncertainties are also important.

One focus of the CCI is to provide products for climate modelers, who increasingly use satellite data to initialize, constrain, and validate models on a wide range of space and time scales (seasonal to centennial). Better predictions require better models, which in turn require reliable observations to evaluate them. The growing use of satellite data is partly due to the increasing resolution, complexity, and range of the physical processes now represented in climate models. Longer records provide opportunities to examine the models over a greater range of situations (e.g., El Niño and other interannual variations), improving the assessment of their reliability.

The second, equally important, focus is a clear need of stable, long-term, and consistent data records for budget closure studies. For this, the interdependence and feedback of variables are studied and estimates of the uncertainties of the budget are obtained. For example, in a recent study (e.g., Loeb et al. 2009) the observed imbalance of energy at the top of the atmosphere is linked to the net heat content of the ocean. To understand such changes, consistent measurements of related variables of ocean and atmosphere are necessary (e.g., sea surface temperature, sea ice, sea level, ice sheets, clouds) along with estimates of their uncertainties. Similar information on the change in mass of glaciers and ice sheets can help constrain the effects on global and regional sea level.

Third, the provision of uniformly processed datasets for reanalysis of the coupled atmosphere (Dee et al. 2011), ocean, and land surface is a major future application of the CCI-generated CDRs. Some will be directly assimilated whereas others will provide boundary conditions for the reanalysis.

This paper outlines the objectives of the CCI and the improvements to be made to satellite datasets. The next section describes the CCI activities in more detail, whereas the "New climate data records" section summarizes the new climate data records for the ECVs being addressed by the CCI and the "Provision and exploitation of datasets" section describes the plans for making the data available to the user and their potential exploitation. 
OVERVIEW OF THE CCI. Out of the 50 ECVs identified by GOCS, 13 have been selected for the CCI (in the current program) where an important contribution can be made to international climate change science with the available data. A total of 10 projects started in 2010, and 3 projects (sea ice, soil moisture, and ice sheets) began in early 2012:

atmosphere: ozone, clouds, aerosols, and greenhouse gases $\left(\mathrm{CO}_{2}, \mathrm{CH}_{4}\right)$;

ocean: sea level, sea surface temperature, ocean color, and sea ice; and

terrestrial: land cover, fire disturbance, soil moisture, glaciers and ice caps, and ice sheets.

The sensors and technologies used for observation and the length of the record vary between ECVs. Figure 1 shows, for all ECVs, which satellite instruments will contribute to the climate data records produced for each ECV. As presented in Fig. 1, the CCI projects use and benefit from the full capacity of globally available satellite-based Earth observation data. Depending on the ECV, the most appropriate satellite instruments are used either for production of datasets or for intercomparison in the validation efforts. The CCI requires some common approaches and activities to be undertaken in parallel by the teams; these common elements are as follows.

An early task for every CCI project was an assessment of the requirements of climate scientists and other users for EObased climate data records for each ECV. This included surveys of scientists, and assessments of established requirements from GCOS, the scientific literature, and statements by other expert groups. In many cases, the user requirement reports for each ECV contributed to the recent GCOS update to the satellite supplement on needs for climate observations (GCOS 2010). The resulting user requirements documents (URDs) are publicly available through the CCI website. Based on interaction with the scientific stakeholders and taking into account existing datasets, each project then defined the most feasible products to address the needs of its core users. Product specification documents (PSDs) describe the CDRs to be generated.

A second aspect of every project is an open process of algorithm intercomparison and selection to define the best available techniques for the production of CDRs. Teams are involved in developing their own algorithms and in performing an objective assessment of alternative approaches. In some cases, it has been possible to engage parties outside of the CCI in contributing datasets for comparison. The related product validation and algorithm selection reports (PVASRs) present the results for each ECV.

Third, each project must specify the long-term needs for a system to deliver EO-based climate data and information for each of the 13 ECVs including descriptions of data access, software, and hardware. Teams prototype and demonstrate the generation of CDRs that are as complete as possible within a research context, for each ECV, to illustrate the outputs of the systems specified. The intention is that many of these prototype systems will be fully commissioned in the future, including joint development across cognate groups of ECVs if appropriate.

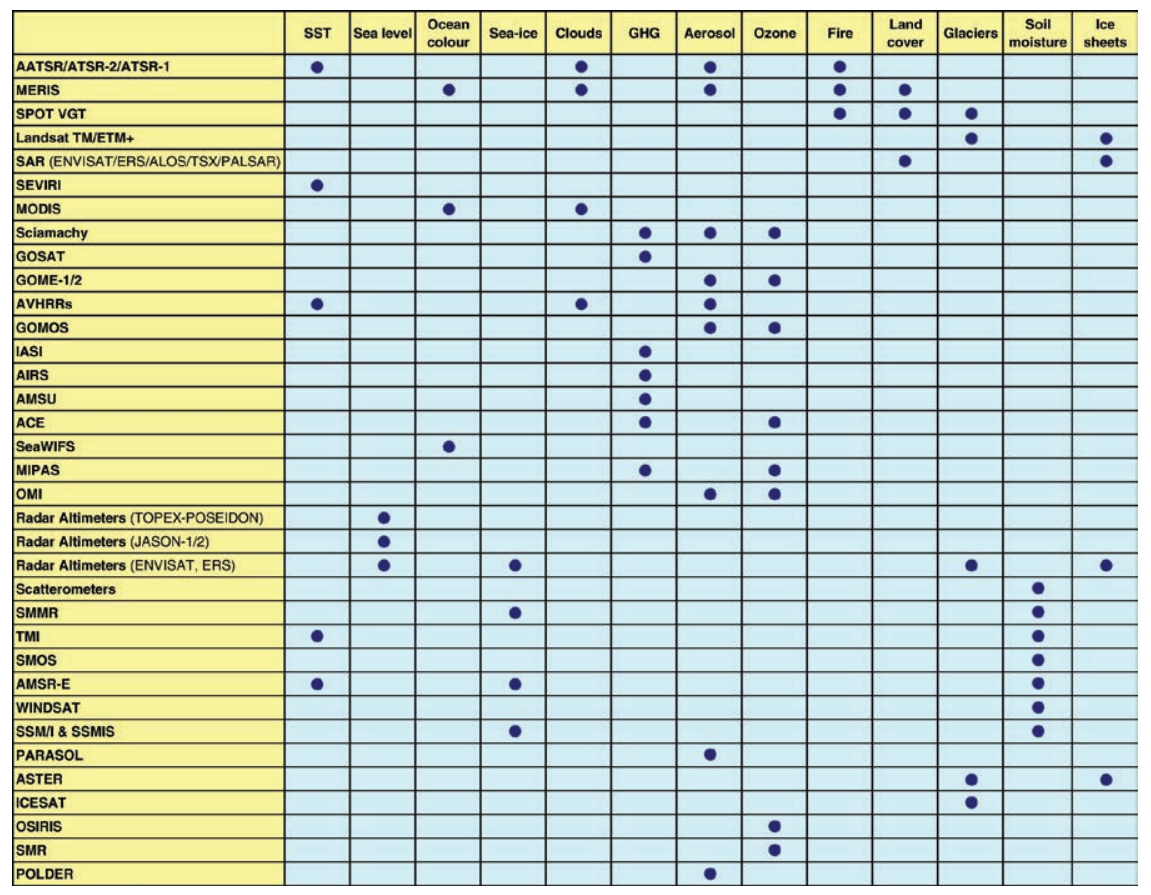

FIG. I. Primary satellite sensors contributing to each ECV in the $\mathrm{CCl}$ program. Other sensors not listed here will also contribute indirectly or through validation activities. A more complete table with all sensors used is available online (at www.esa-cci.org). 
Fourth, the prototype products will be openly and independently verified, validated, and assessed for their utility to climate science, by independent teams not involved in the product development.

All four elements are being pursued consistently with principles and practices designed to maximize the benefit to climate science. Input data and output products will be available, all algorithms will be described in open literature and reports, and data standards have been adopted to make data readily usable by climate modelers and other groups. This was mostly not the case for previous CDRs, which made it difficult for modelers to use the datasets, but has been a key focus for the CCI. All projects will promote the new CDRs more actively to the climate research community to ensure they are used as soon as they become available. To facilitate these interactions, a "climate modelling users group" (CMUG) was set up at the same time as the projects. Part of the work for the CMUG will be to help with dataset promotion and to study the consistency between different ECV CDRs, but their main aim is to ensure that teams' activities take full account of the needs of climate modelers and reanalyses. These can vary across different modeling activities so each CCI project has worked to develop attributes of their ECV data product of most benefit to their users (as outlined

TABLE I. Added value of ESA CCI climate data records for the marine ECVs being developed. The last column presents an overview of challenges investigated by the $\mathrm{CCl}$ projects.

\begin{tabular}{|c|c|c|c|}
\hline \multicolumn{4}{|c|}{ A: Marine } \\
\hline ECVs & Precursor and its attributes & $\begin{array}{l}\text { CCI CDR expected product } \\
\text { improvements and temporal coverage }\end{array}$ & $\begin{array}{l}\text { Scientific challenges the } \\
\text { products will address }\end{array}$ \\
\hline SST & $\begin{array}{l}\text { Along-Track Scanning Radiometer } \\
\text { (ATSR) Reprocessing for Climate: } \\
\text { Independent, stable SST for } \\
\text { I99I-2009, 0.I K point accuracy, } \\
\text { relative sparse sampling from } \\
\text { narrow-swath ATSRs }\end{array}$ & $\begin{array}{l}\text { - Cross-calibrate Advanced Very High Resolution } \\
\text { Radiometer (AVHRR) brightness temperatures } \\
\text { to ATSRs, giving AVHRR density of sampling with } \\
\text { ATSR-based accuracy, stability, and independence } \\
\text { - A } 20 \text {-yr, independent, accurate (0.I K), } \\
\text { high-stability CDR } \\
\text { - Characterization of uncertainty components at all } \\
\text { spatiotemporal scales } \\
\text { - User-friendly data formats and documentation } \\
\text { - Temporal coverage: } 1991-2010\end{array}$ & $\begin{array}{l}\text { - Consistent, stable SSTs with } \\
\text { higher coverage } \\
\text { - Realistic uncertainties to } \\
\text { inform model comparisons and } \\
\text { assimilation } \\
\text { - Independence from in } \\
\text { situ records for rigorous } \\
\text { reassessment of recent marine } \\
\text { climate change }\end{array}$ \\
\hline $\begin{array}{l}\text { Ocean } \\
\text { color }\end{array}$ & $\begin{array}{l}\text { GlobColour: Merged products } \\
\text { including chlorophyll, spectral } \\
\text { values of water-leaving radiance, } \\
\text { and inherent optical properties at } \\
\text { specific wavelengths }\end{array}$ & $\begin{array}{l}\text { - Multiple merged products including chlorophyll, } \\
\text { spectral values of water-leaving radiance, and } \\
\text { spectrally resolved inherent optical properties } \\
\text { - Improved spatial coverage (e.g., at daily and } \\
\text { weekly scales) } \\
\text { - Retrieval of variable spectral shapes of } \\
\text { phytoplankton optical properties } \\
\text { - Temporal coverage: } 1997-2012\end{array}$ & $\begin{array}{l}\text { - The improved ocean color } \mathrm{CCl} \\
\text { product will support trend } \\
\text { studies in marine ecosystem } \\
\text { properties } \\
\text { - Removing spurious trends } \\
\text { (arising from intersensor } \\
\text { differences) of current merged } \\
\text { ocean color data }\end{array}$ \\
\hline $\begin{array}{l}\text { Sea } \\
\text { level }\end{array}$ & $\begin{array}{l}\text { Archiving, Validation, and } \\
\text { Interpretation of Satellite } \\
\text { Oceanographic data (AVISO) } \\
\text { radar altimeter sea level record } \\
\text { from } 1992-2012\end{array}$ & $\begin{array}{l}\text { - The global mean sea level derived from ESA } \\
\text { missions [European Remote Sensing Satellite-I } \\
(E R S-I) / E R S-2 \text {, Envisat] has been significantly } \\
\text { improved and the uncertainty has decreased from } \\
0.5-0.6 \mathrm{~mm} \mathrm{yr}^{-1} \text { to }<0.3{\mathrm{~mm} \mathrm{yr}^{-1}}^{-} \text {Combines all available missions and covers high } \\
\text { latitude oceans and coastal zones } \\
\text { - Regional mean sea level trends have also been } \\
\text { improved } \\
\text { - Temporal coverage: } 1992-2010\end{array}$ & $\begin{array}{l}\text { - Significant improvements to } \\
\text { meet climate standards } \\
\text { - Reduction in uncertainty of } \\
\text { the global mean trend below } \\
0.3 \mathrm{~mm} \mathrm{yr}^{-1} \\
\text { - Different sources of sea level } \\
\text { variability distinguished (ocean } \\
\text { thermal expansion, ice sheets, } \\
\text { land water, glaciers) }\end{array}$ \\
\hline Sea ice & $\begin{array}{l}\text { EUMETSAT Satellite Application } \\
\text { Facility on Ocean and Sea } \\
\text { Ice (OSI SAF) arctic ice } \\
\text { concentration product }\end{array}$ & $\begin{array}{l}\text { - Generation of the first homogeneous and } \\
\text { validated ice thickness dataset for the Arctic, } \\
\text { based on radar altimeter data } \\
\text { - Homogenous validated ice concentration datasets } \\
\text { for the Arctic and Antarctic from } 1979 \text { to } 2012 \\
\text { with error estimates based on validation data }\end{array}$ & $\begin{array}{l}\text { - Improve global climate model } \\
\text { simulations of sea ice } \\
\text { - Understand the interaction } \\
\text { between sea ice, ocean, and } \\
\text { atmosphere }\end{array}$ \\
\hline
\end{tabular}


in Tables 1-3). For example, to evaluate predictions of climate change, long-term stability of observations and its associated uncertainty are critically important. In contrast, stability is less crucial for model process studies, where spatial and temporal resolution become more important.

TABLE 2. As in Table I, but for the GCOS atmospheric ECVs.

\section{B: Atmosphere}

\begin{tabular}{|c|c|c|c|}
\hline ECVs & $\begin{array}{l}\text { Precursor and its } \\
\text { attributes }\end{array}$ & $\begin{array}{l}\text { CCI CDR expected product } \\
\text { improvements and temporal coverage }\end{array}$ & $\begin{array}{l}\text { Scientific challenges the } \\
\text { products will address }\end{array}$ \\
\hline Clouds & $\begin{array}{l}\text { International Satellite Cloud } \\
\text { Climatology Project (ISCCP): } \\
\text { Polar satellites, merged with } \\
\text { geostationary satellites; } \\
\text { two-channel cloud detection } \\
\text { approach }\end{array}$ & $\begin{array}{l}\text { - Cloud } \mathrm{CCl} \text { combines both European/ESA and } \\
\text { U.S. instruments } \\
\text { - An optimal estimation retrieval scheme will be } \\
\text { consistently applied to different instruments } \\
\text { to produce a long time series (with improved } \\
\text { temporal and spatial sampling, including } \\
\text { uncertainty estimates of the cloud properties) } \\
\text { - The products will have improved spectral } \\
\text { consistency using a five-channel approach. } \\
\text { - Level-I calibration with advanced sensors } \\
\text { - Initial temporal coverage: } 2007-09 \text { with the } \\
\text { intention to go for 1982-2013 }\end{array}$ & $\begin{array}{l}\text { - The role of clouds in climate } \\
\text { is crucial and remains a main } \\
\text { uncertainty in climate science } \\
\text { - Measurements of cloud } \\
\text { properties with associated } \\
\text { uncertainty estimates will help } \\
\text { to identify different sources of } \\
\text { uncertainty }\end{array}$ \\
\hline Aerosol & $\begin{array}{l}\text { GlobAerosol: ATSR-2, } \\
\text { Advanced Along-Track } \\
\text { Scanning Radiometer (AATSR), } \\
\text { Medium Resolution Imaging } \\
\text { Spectrometer (MERIS), and } \\
\text { Spinning Enhanced Visible and } \\
\text { Infrared Imager (SEVIRI) merged } \\
\text { products: Aerosol optical depth } \\
\text { (AOD) } 0.55 \text { and } 0.87 \mu \mathrm{m} \\
\text { ESA Grid Processing on Demand } \\
\text { (G-POD): Full I3-yr ATSR-2/ } \\
\text { AATSR data series }\end{array}$ & $\begin{array}{l}\text { - The products have improved accuracy, added } \\
\text { uncertainty characterization, and quality flags } \\
\text { - Using new instruments and new or improved } \\
\text { algorithms } \\
\text { - Additional retrieval parameters } \\
\text { - Initial temporal coverage: } 2008 \text {, to be } \\
\text { extended to } 1995-2012\end{array}$ & $\begin{array}{l}\text { - Understand and thereby reduce } \\
\text { differences between aerosol } \\
\text { products retrieved from different } \\
\text { sensors } \\
\text { - Quantify uncertainties to } \\
\text { establish tighter constraints in } \\
\text { aerosol-climate modeling }\end{array}$ \\
\hline $\begin{array}{l}\text { Green- } \\
\text { house } \\
\text { gases } \\
\text { (GHGs) }\end{array}$ & $\begin{array}{l}\text { Initial Scanning Imaging } \\
\text { Absorption Spectrometer for } \\
\text { Atmospheric Cartography } \\
(\mathrm{SCIAMACHY)} \mathrm{(e.g.,} \mathrm{2003-05} \\
\mathrm{CO}_{2} \text { ) and first Greenhouse } \\
\text { Gases Observing Satellite (GOSAT) } \\
\text { (launch 2009). }\end{array}$ & $\begin{array}{l}\text { - The } \mathrm{CCl} \text { project will generate global time } \\
\text { series of column-averaged mixing ratios of } \\
\mathrm{CO}_{2} \text { and } \mathrm{CH}_{4} \text { from SCIAMACHY and GOSAT } \\
\text { - Improved quality (reduced biases) and better } \\
\text { error characterization } \\
\text { - Extended temporal coverage: } 2003-10\end{array}$ & $\begin{array}{l}\text { - Climate prediction requires a good } \\
\text { understanding of the sources and } \\
\text { sink of the two major GHGs carbon } \\
\text { dioxide }\left(\mathrm{CO}_{2}\right) \text { and methane }\left(\mathrm{CH}_{4}\right) \\
\text { - Provide global atmospheric } \\
\text { distributions of } \mathrm{CO}_{2} \text { and } \mathrm{CH}_{4} \text { to } \\
\text { enhance our knowledge on their } \\
\text { regional sources and sinks }\end{array}$ \\
\hline Ozone & $\begin{array}{l}\text { Total ozone: e.g., Global } \\
\text { Ozone Monitoring Experiment } \\
\text { (GOME) Data Processor } 5 \\
\text { (GOME GDP 5) } \\
\text { Nadir profiles: e.g., GOME2- } \\
\text { OPERA } \\
\text { Limb profiles: e.g., Envisat } \\
\text { QWGs }\end{array}$ & $\begin{array}{l}\text { - For total ozone a harmonized GOME, } \\
\text { SCIAMACHY, and GOME2 data product with } \\
\text { I\% accuracy is planned } \\
\text { - For nadir profiles, a harmonized time series } \\
\text { of GOME, SCIAMACHY, GOME2, and } \\
\text { Ozone Monitoring Instrument (OMI) will be } \\
\text { generated with improved information content } \\
\text { in the troposphere } \\
\text { - For limb profiles a merged Envisat + } \\
\text { Advanced Composition Explorer (ACE), Odin } \\
\text { Spectrometer and Infrared Imaging System } \\
\text { (OSIRIS), and Sub-Millimetre Radiometer } \\
\text { (SMR) dataset is planned, with major } \\
\text { improvements in the error analysis } \\
\text { - Temporal coverage: I995-20II (nadir sensors) } \\
\text { and 200I-II (limb sensors) }\end{array}$ & $\begin{array}{l}\text { - The evolution of ozone is inti- } \\
\text { mately coupled to climate change } \\
\text { - The products are essential to help } \\
\text { assess the fate of atmospheric } \\
\text { ozone and better understand its } \\
\text { link with anthropogenic activities }\end{array}$ \\
\hline
\end{tabular}


TABLE 3. As in Table I, but for the GCOS terrestrial ECVs.

\section{C: Terrestrial}

\begin{tabular}{|c|c|c|c|}
\hline ECVs & $\begin{array}{l}\text { Precursor and its } \\
\text { attributes }\end{array}$ & $\begin{array}{l}\text { CCI CDR expected product } \\
\text { improvements and temporal coverage }\end{array}$ & $\begin{array}{l}\text { Scientific challenges the } \\
\text { products will address }\end{array}$ \\
\hline $\begin{array}{l}\text { Fire } \\
\text { disturbance }\end{array}$ & $\begin{array}{l}\text { European: GlobCarbon: } \\
\text { Limited validation, } \\
\text { lack of uncertainty } \\
\text { characterization } \\
\text { National Aeronautics } \\
\text { and Space Administration } \\
\text { (NASA): Moderate } \\
\text { Resolution Imaging } \\
\text { Spectroradiometer (MODIS) }\end{array}$ & $\begin{array}{l}\text { - Burned area (BA) will be obtained from merging } \\
\text { three European sensors: first BA product } \\
\text { derived from MERIS } \\
\text { - Attributes will include information for climate } \\
\text { modelers: confidence levels, burned covers, and } \\
\text { fire size distribution } \\
\text { - Temporal coverage: } 1995-2009 \text { with } 3 \text { global } \\
\text { years }\end{array}$ & $\begin{array}{l}\text { - To improve mapping of burned } \\
\text { areas and the use of this } \\
\text { information for global vegetation } \\
\text { modeling, as well as the } \\
\text { estimation of fire emissions to } \\
\text { the atmosphere }\end{array}$ \\
\hline Soil moisture & $\begin{array}{l}\text { Water Cycle Multimission } \\
\text { Observing Strategy } \\
\text { (WACMOS): One merged } \\
\text { active/passive dataset for } \\
\text { 1978-2010 }\end{array}$ & $\begin{array}{l}\text { - Soil moisture } \mathrm{CCI} \text { merges individual satellite } \\
\text { records into consistent harmonized, globally } \\
\text { gridded, multisatellite, daily, surface soil } \\
\text { moisture dataset } \\
\text { - Three soil moisture products will be produced: } \\
\text { one based only on passive microwave data, one } \\
\text { on active microwave data, and one on merged } \\
\text { active/passive data } \\
\text { - Soil moisture CCI will improve retrieval } \\
\text { accuracies and consistency over time and space } \\
\text { - Temporal coverage: } 1978-2010\end{array}$ & $\begin{array}{l}\text { - Soil moisture can improve } \\
\text { temperature and precipitation } \\
\text { predictions in climate models } \\
\text { - Quantify impact of global } \\
\text { warming on drought and flood } \\
\text { occurrence } \\
\text { - Study response of permafrost to } \\
\text { global warming }\end{array}$ \\
\hline Glaciers & $\begin{array}{l}\text { GlobGlacier: Global } \\
\text { Terrestrial Network } \\
\text { for Glaciers (GTN-G) } \\
\text { [World Glacier Monitoring } \\
\text { Service/Global Land Ice } \\
\text { Measurements from Space } \\
\text { (WGMS/GLIMS)] WGI and } \\
\text { GLIMS database were only } \\
\text { 50\% complete before }\end{array}$ & $\begin{array}{l}\text { - Glacier CCI has substantially contributed to pro- } \\
\text { ducing the first globally complete dataset of glacier } \\
\text { outlines; this comes with an improved error } \\
\text { characterization of the glacier area products } \\
\text { - Progress has also been made in automating and/ } \\
\text { or making consistent the data processing for } \\
\text { elevation change and velocity products. } \\
\text { - Temporal coverage: } 1984-2012\end{array}$ & $\begin{array}{l}\text { - Glaciers are sensitive indicators } \\
\text { of climate change and strongly } \\
\text { contribute to sea level rise } \\
\text { - On a regional scale they are } \\
\text { important hydrologically (e.g., for } \\
\text { water resources and agriculture } \\
\text { hydropower) and can constitute } \\
\text { a serious natural hazard }\end{array}$ \\
\hline Land cover & $\begin{array}{l}\text { GlobCover 2005/ } \\
\text { GlobCover 2009/ } \\
\text { GlobCorine }\end{array}$ & $\begin{array}{l}\text { - First consistent series of } 300-\mathrm{m} \text { global land- } \\
\text { cover products, derived using the full archive of } \\
\text { different sensors } \\
\text { - Characterization of the land surface by a stable } \\
\text { (land-cover state in } 22 \text { classes) and a dynamic } \\
\text { (land-cover conditions) component including } \\
\text { their respective interannual variability } \\
\text { - Aggregation tool to transform maps into plant } \\
\text { functional types (PFTs) } \\
\text { - Temporal coverage: three } 5 \text {-yr epochs from } \\
\text { I998 to } 2002 \text {, from } 2003 \text { to } 2007 \text {, and from } \\
2008 \text { to } 2012\end{array}$ & $\begin{array}{l}\text { - Land-cover data and related } \\
\text { uncertainties will support a better } \\
\text { surface parameterization (plant } \\
\text { functional types) in dynamic } \\
\text { global vegetation models and in } \\
\text { integrated assessment models } \\
\text { - Land cover is used to assess } \\
\text { the effects of land-use and } \\
\text { land-cover feedbacks in } \\
\text { terms of climate impacts and } \\
\text { vulnerabilities }\end{array}$ \\
\hline Ice sheets & $\begin{array}{l}\text { Ice, Cloud, and Land } \\
\text { Elevation Satellite (ICESat) } \\
\text { (mean surface elevation } \\
\text { change) spatial scale } 50 \mathrm{~km} \\
\text { (2003-07) } \\
\text { Ice front position changes } \\
\text { (1972-2010) } \\
\text { Mass balance (2000-10) }\end{array}$ & $\begin{array}{l}\text { - Focus will be on the Greenland ice sheet and } \\
\text { providing more precise ice-sheet monitoring } \\
\text { from SAR and optical observation } \\
\text { - The ice sheets ECV products encompass four } \\
\text { key parameters: surface elevation change } \\
\text { (SEC), ice velocity (IV), calving front location, } \\
\text { and grounding line locations } \\
\text { - Focus will be on producing high-resolution data } \\
\text { in the marginal ice-sheet areas for SEC and IV } \\
\text { and putting together long, continuous records, } \\
\text { particularly for SEC } \\
\text { - Temporal coverage: } 1991-2012\end{array}$ & $\begin{array}{l}\text { - Changes in ice sheet mass have } \\
\text { consequences for global and } \\
\text { regional sea level change, as well } \\
\text { as the Arctic climate } \\
\text { - Ice sheet models, designed to } \\
\text { understand ice-sheet mechan- } \\
\text { ics, are currently not using the } \\
\text { full capacity of satellite data } \\
\text { in validations so IS CCI data } \\
\text { products will be designed to fit } \\
\text { this purpose } \\
\text { - Understanding of ice flow } \\
\text { changes and outlet glaciers }\end{array}$ \\
\hline
\end{tabular}


THE NEW CLIMATE DATA RECORDS. The aim of all $13 \mathrm{ECV}$ projects is to provide improved CDRs relative to existing satellite products. Tables 1-3 provide a summary of the improvements expected from CCI projects, based on the requirements analysis and the outcome of the algorithm selection process (as outlined in the "Overview of the CCI" section). The addition of uncertainty information is an integral part of all $13 \mathrm{ECVs}$, although each dataset also brings its own individual benefits, also described in Tables 1-3. As shown in Fig. 1, some ECVs will include sensors not previously used for CDR generation (e.g., clouds, ocean color, fire disturbance), others provide better coverage in time and space (e.g., land cover, ice sheets), while others were previously unavailable (e.g., glaciers, soil moisture).

The following sections provide a short introduction to the main scientific challenges to which the GCOS ECVs and CCI can contribute. The specific challenges for each individual CCI are summarized and presented in Tables 1-3 per GCOS ECV domain. An explanation of the elements common to all CCI projects (as already introduced in the "Overview of the CCI" section) is explained below: user requirements analysis and specifications, open algorithm intercomparison, and validation and evaluation

Main challenges targeted from $\mathrm{CCl}$ projects. CHALLENGES IN THE MARINE ECV DOMAIN. The marine ECVs in the CCI are important indicators of climate change. Sea level rise can be thought of as an index of climate that integrates the variability and interactions of nearly all the components of the Earth system (ocean, land, cryosphere, and atmosphere). As such, it is used in climate change detection and attribution studies. However, regional scale sea level changes are particularly challenging to measure, as it is where the uncertainty is largest (e.g., Table 1). The same applies to sea surface temperature (SST), which is also prescribed in atmospheric reanalyses and ocean data assimilation. Ocean color (i.e., spectrally resolved reflectances in the visible domain) reveals variability in the marine ecosystem and provides a fingerprint of modifications of the ecosystem under a changing climate. Joint investigation of marine ECV datasets, such as sea ice parameters, SST, and sea level estimates, is needed to provide further insight into how climate change affects vulnerable areas of the globe, particularly the Arctic. Overall, the main challenges are to specify and distinguish the different sources of variability and characterize and remove intersensor spurious trends (e.g., as given in Table 1). To understand the climate change processes and their interdependence at the ocean surface all selected variables need to be investigated in a coherent way.

Challenges in the atmospheric ECV domain. In the atmospheric ECV domain, aerosols and clouds are an important component of the global energy and water cycle. They interact with many climate variables, such as SST, the radiation budget, precipitation, and fires. Clouds and aerosols reflect incoming sunlight and absorb infrared emissions from Earth's surface, but their feedback mechanisms remain a major source of uncertainty for current climate and future projections. Aerosols still have the largest uncertainty in the forcing of the climate system (Solomon et al. 2007). Thus a major challenge target is to quantify the cloud-aerosol forcing and aerosol uncertainty (Table 2).

Ozone and greenhouse gases (GHGs) are important radiatively active gases in the atmosphere. Carbon dioxide $\left(\mathrm{CO}_{2}\right)$, methane $\left(\mathrm{CH}_{4}\right)$, and tropospheric

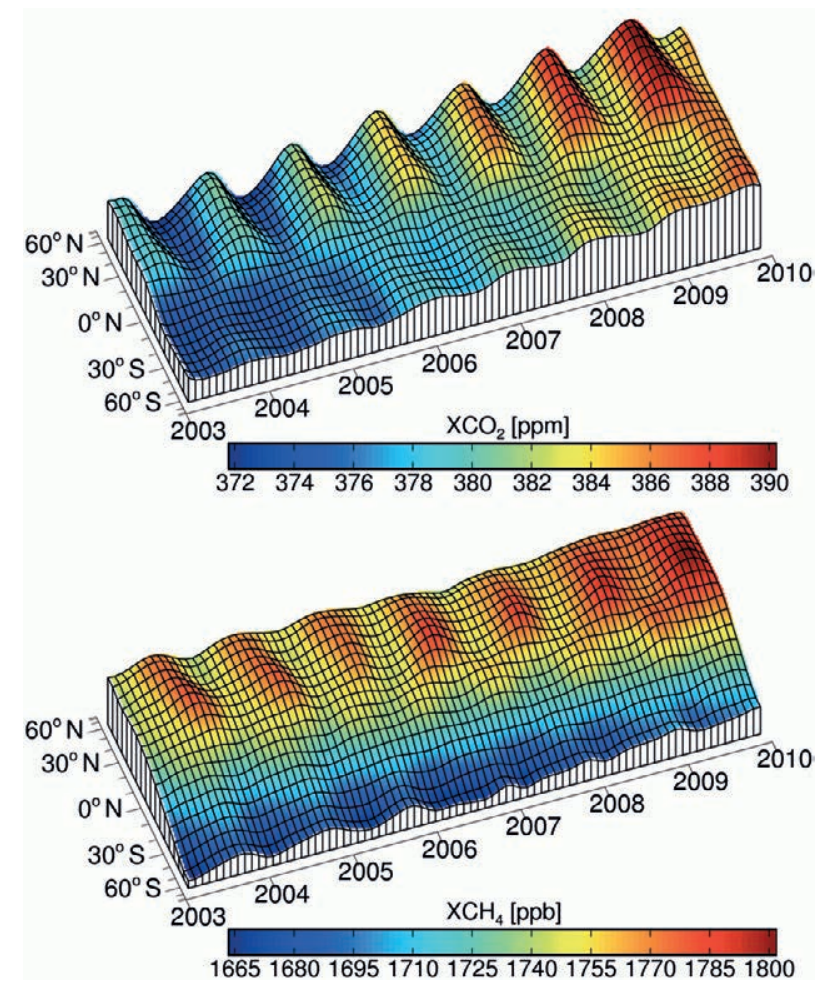

FIG. 2. Latitude-time series of atmospheric (top) $\mathrm{CO}_{2}$ and (bottom) $\mathrm{CH}_{4}$ obtained from SCIAMACHYI Envisat (Schneising et al. 20II). In (top), the rising $\mathrm{CO}_{2}$ levels, the $\mathrm{CO}_{2}$ seasonal cycle, and the hemispheric differences in $\mathrm{CO}_{2}$ resulting from greater biomass and anthropogenic emissions in the Northern Hemisphere are clearly visible. In (bottom), the seasonal cycle of methane is primarily due to wetland emissions. The reason for the recent methane increase is not yet well understood. 
ozone are the three anthropogenic GHGs most responsible for global warming. Figure 2 shows the rising $\mathrm{CO}_{2}$ levels (Fig. 2, top) and methane (Fig. 2, bottom) observed with SCIAMACHY since 2003 and their seasonal cycle averaged per latitude band.

However, the depletion of the ozone layer in the ' 80 s and its slow recovery has tended to cool Earth's stratosphere (e.g., Solomon 2007), so key issues for climate are the long-term trends in ozone and the complex interactions with the evolution of ozonedepleting substances and other GHGs. Accurate knowledge of the spatial and temporal distribution of ozone and the GHGs (e.g., $\mathrm{CO}_{2}$ and $\mathrm{CH}_{4}$ ) is required to quantify regional sources and sinks but also to understand the overall feedback between climate change and related changes in atmospheric transport and in atmospheric composition.

Challenges In the terrestrial ECV domain. The terrestrial ECVs play important roles in the hydrological and carbon cycles and have direct links to human activity. Changes in the land surface interact with the atmosphere, cryosphere, and ocean on different time and spatial scales, resulting in a series of positive and negative feedbacks. Soil moisture is a key driver of the atmosphere-surface exchange of water, energy, and carbon as it is a limiting factor in evapotranspiration (Jung et al. 2010). However, a major challenge is to reduce the considerable uncertainty of the magnitude of this feedback, which is partly due to a lack of observational data (Table 3). Forest fires play an important role in both gas emissions and vegetation dynamics, but it is challenging to make reliable estimates of the total area affected without proper uncertainty characteristics. Glaciers, icecaps, and ice sheets show obvious visible responses to subtle changes either compensating or exaggerating integrated effects from atmosphere, land, and ocean variables. Challenges in these areas are to establish a globally complete baseline map of glaciers and to provide datasets for the understanding of ice-sheet mechanics, which are both addressed by the CCI (Table 3). Understanding elevation changes, velocity fields, and associated mass fluxes of glaciers and icecaps will inform the hydrological cycle and provide essential constraints on understanding their contribution to sea level rise (e.g., Cogley 2009; Cazenave and Nerem 2004).

Requirement analysis and specification. All projects started with an analysis of user requirements, in which the GCOS requirements (GCOS 2010) were used as a baseline, accompanied by a survey of the climate change community on the products needed to improve climate model outputs and advance climate research. Within each project, a dedicated "climate research group" helped to ensure that a broad range of users were surveyed for their views and that key science bodies were enlisted to help review the resulting user requirement document. Surveys of existing CDRs for each ECV were also undertaken.

For a few ECVs (e.g., sea level, clouds, sea ice, and SST), long, global satellite data records are already available, so the focus for these projects has been on identifying the priorities for improvements of the datasets. One aspect that needs careful consideration for each variable is the requirement for long-term stability. The ECV product improvements have been dictated by the variety of different applications identified by the users. For example, satellite observations of cloud properties span more than 30 years and are complemented by global satellite-based climatologies of cloud properties that continue to be developed [e.g., Pathfinder Atmosphere (PATMOS), ISCCP, MODIS, Satellite Application Facility on Climate Monitoring (CM SAF)]. Although these long-term data exist, clouds are notoriously difficult to measure because of the number of complex variables involved in obtaining cloud properties. To understand the quality and limitations of available cloud climatologies, the Global Energy and Water Cycle Experiment (GEWEX) cloud assessment (Stubenrauch et al. 2012) summarized satellite-derived cloud properties and characterized differences and errors. An accuracy of better than $10 \%$ in cloud cover is required for process studies, but a much higher long-term stability of $1 \%$ per decade is needed to detect climate change (GCOS 2011). Thus, the outcome of the requirements analysis for cloud CCI was a focus on accuracy and stability.

CCI land cover provides a contrasting example; the existing global land-cover datasets (e.g., Defourny et al. 2012) have been produced from single satellite sensors for a given epoch but are not fully consistent (Jung et al. 2006). Furthermore, land-cover classifications are not consistent with plant functional types-a parameterization concept used in climate models. Long time series of high-resolution land surface reflectance are yet to be processed in a coherent way to deliver consistent land-cover information for decadal time scales. The results of the land-cover requirements analysis therefore focused on issues of consistency (see Table 3) and relevance to climate modeling and, in particular, on the consistency between ECVs, such as fire, glaciers, land surface albedo, and land cover. 
Open exercise on retrieval algorithm intercomparison. Each ECV project includes an open exercise to develop, test, and select the most suitable (i.e., best performing and up to date) algorithms for generating their CDR in the light of the requirements analysis. Referred to as the "round robin" process, external parties were invited to participate by submitting their own algorithms for assessment, alongside those chosen by the project. Each project has an "Earth observation science team" to lead this process that is composed of experts in developing methodologies and algorithms for the generation of climate-relevant datasets. The round-robin process varied depending on how established and unified algorithm development has been historically.

For example, the many algorithms developed for aerosol retrieval had not previously been compared on such a comprehensive basis. Aerosol CCI considered eight algorithms and thoroughly tested and improved their retrieval methods, underlying assumptions, uncertainties, as well as the effects of cloud masking and representation of the surface. A common set of aerosol components, representative for all possible situations, was used. Figure 3 shows a comparison of global gridded $1^{\circ}$ monthly baseline datasets of those four submitted algorithms using AATSR at the start of the project (Fig. 3, red box) with their algorithm intercomparison datasets, after the second round-robin evaluation (Fig. 3, blue box), where improvements have been introduced into the retrieval schemes. It is clearly visible that all algorithms have improved substantially as a result of the joint efforts and the differences between the algorithms compared against external reference datasets (here MODIS is used: Fig. 3, middle) have decreased. Aerosol CCI decided to use MODIS as reference baseline based on their requirement analysis and as an important available aerosol precursor dataset. Furthermore, the project evaluated and validated the dataset using the global AeroCom network. Based on

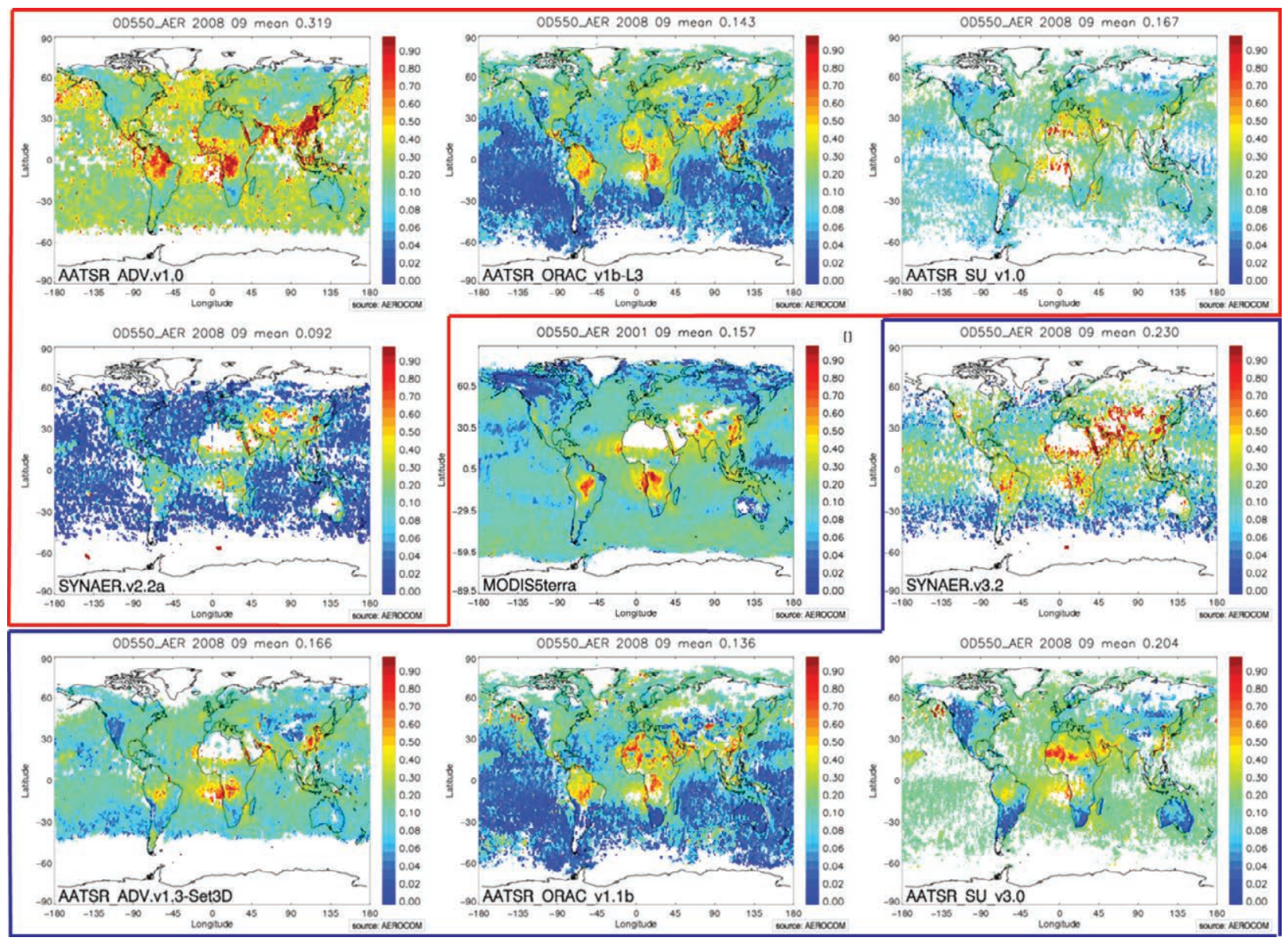

FIG. 3. Results from the aerosol $\mathrm{CCl}$ project comparing global gridded, $\mathrm{I}^{\circ}$ monthly baseline AOD datasets at the start of the project of four submitted algorithms using AATSR (red box) with their algorithm-comparison exercise datasets after the second evaluation (blue box). To evaluate the retrieval improvement, (middle) MODIS aerosol data have been chosen as reference in this figure. 
the results, algorithms were then selected to produce prototype CCI datasets.

Glaciers CCI approached the round robin from a different perspective as a systematic intercomparison of glacier outlines resulting from different methods was not available thus far. This comparison showed that all algorithms performed equally well for clean ice. To assess the accuracy of automatically derived glacier outlines (i.e., glacier area), the project compared them to manually digitized datasets, which are considered more accurate. This revealed that there was no discernible difference in accuracy between the two methods and that the key source of uncertainty comes from the interpretation of debris-covered glacier parts. Glaciers CCI also found that the precision of the glacier outlines do not increase when higher-resolution datasets are used, mainly because debris cover identification is equally difficult at high resolutions (Paul et al. 2013).

Validation and evaluation. Validation is the comparison of the satellite ECV products with validation data, in order to be able to make statements about the quality of the products. For a CDR, validation includes but goes beyond the calculation of comparison statistics between satellite ECV and the validation data. Such statistics provide information about the accuracy (biases) and precision (scatter) in products, provided the errors in the validation data are understood and accounted for.

For CDRs, other aspects of quality are also important. The stability of products is the degree to which the satellite ECV accuracy is constant over time and is a component in the error budget for any calculation of geophysical trends from the dataset. Stability can be difficult to quantify if validation data are themselves of uncertain or inadequate stability.
Sometimes, no independent long-term validation data are available. For example, in the case of SST, drifting buoy datasets are usually used for validation (e.g., Embury et al. 2012). Drifting buoys are made by various manufacturers whose buoys are deployed in proportions that vary over time, so the overall stability of the drifting buoy network is not assured at the $3 \mathrm{mK} \mathrm{yr}^{-1}$ level specified by GCOS (2011). However, maintained moored buoys, such as the global tropical moored buoy array, seem to be more suitable for stability analysis (Merchant et al. 2012; Fig. 4). Quantifying the uncertainty in a stability estimate requires understanding of temporal correlation in errors, and CCI projects are sharing experiences in tackling this problem.

\section{PROVISION AND EXPLOITATION OF}

DATASETS. The use of satellite datasets for climate research has been limited to date because of several constraints (e.g., length of datasets and inconsistencies), although notable exceptions include the top-of-atmosphere Earth radiation budget, sea surface height, and the ISCCP datasets. However, with the increasing complexity of climate models, the need for satellite datasets covering more variables is clear. Some of the CCI datasets will be new products not previously available to the research community, while others will be improvements (e.g., higher quality and addition of uncertainties) and extensions to existing data records, as described in Table 1 . The availability of observation simulators (Bodas-Salcedo et al. 2011) for CDRs will be a vital component to enable optimal use of these data in models as was demonstrated with ISCCP data (Williams and Webb 2009). Where appropriate, observation simulators will be generated for CDRs produced by the CCI to facilitate more direct comparisons of the observations with model variables.

One benefit of having 13 simultaneous projects in the CCI will be the consistency between some of the ECVs (e.g., aerosol and cloud, SST and sea ice, GHG and fire/land cover/ soil moisture) in the new CCI datasets. In its first phase, the CCI will achieve technical consistency (common format, metadata standards and agreed vocabulary, and harmonized documentation); for 
the next phase, a common access portal for data and documentation has been proposed and issues of scientific consistency (consistent auxiliary datasets, consistent dynamical masks for clouds and ice, and documented cross-ECV sensitivities of corrections applied) are under investigation. The CMUG will study the consistency between some CCI datasets by examining the various responses to anomalies (e.g., El Niño, Pinatubo) in each dataset and also through assimilation in reanalyses and in defining surface fields. Another benefit is consistency for the input radiances from the satellite instruments and auxiliary datasets [e.g., European Centre for Medium-Range Weather Forecasts (ECMWF) Interim Re-Analysis (ERA-Interim) model fields] used for the generation of all CDRs. A common year (2008) has been defined where all ECV teams will provide a dataset in order to allow initial studies on consistency across variables as well as budget closure studies.

A desirable feature of the CCI is the characterization of uncertainties for each variable, which are crucial to modelers for applications such as assimilation in reanalyses, assessing model processes, and interpreting long-term trends in parameters. The characterization of uncertainty includes not only validation with reference data but also error propagation from the input calibrated radiances through to the final products. An ensemble of possible solutions for a retrieved ECV dataset is being explored as one way to assess the uncertainty. Later in the project, the time span of the datasets will be maximized to provide better opportunities for monitoring long-term changes and trends.

All CCI data will be openly available free of charge to interested users from the projects via their own project website and the overarching website (see www.esa-cci.org). In addition, access is planned through a portal on the Earth System Grid (www .earthsystemgrid.org/) commonly used by climate modelers. Observations for Model Intercomparison Projects (Obs4MIPS; Teixeira et al. 2011) is also an activity that makes observational products available to climate modelers with which the CCI is engaging. This ensures modelers will have good visibility of, and easy access to, the CCI datasets when they are released in the standard Network Common Data Form Climate and Forecast $[\mathrm{NetCDF}(\mathrm{CF})]$ format. This is a significant step forward compared to previous satellite CDRs, which were made available to the community on a more ad hoc basis. Other CDRs with different applications (e.g., reference datasets: e.g., land cover, glaciers) are made available on public servers for download.
CONCLUSIONS. This paper presented the objectives and scope of ESA's Climate Change Initiative, outlining the approach on delivering climate data records based on satellite data with characteristics optimized for climate research applicants. The CCI targets not only the climate modeling and reanalysis communities, which are embedded in the program through a climate modeling users group, but also many other applications. The current work is prototyping future science-driven operational systems. The close involvement of the scientific community will ensure the program reflects the best available methodologies for creating climate-quality datasets.

The CCI datasets will be used for many applications including detection and attribution of climate change, assimilation in long-term reanalyses, assessing climate model performance, and initialization and provision of boundary conditions for seasonal to centennial forecasts. They will also support future research for international programs such as the World Climate Research Programme (WCRP) Data Council and underpin the planned global climate services, designed to provide climate information to governments, industry, and the general public. In setting up a strong focus on uncertainty characterization and consistency, CCI will provide new opportunities to make progress in our understanding of the Earth system.

\section{REFERENCES}

Bodas-Salcedo, A., and Coauthors, 2011: COSP: Satellite simulation software for model assessment. Bull. Amer. Meteor. Soc., 92, 1023-1043.

Cazenave, A. S., and R. S. Nerem, 2004: Present-day sea level change: Observations and causes. Rev. Geophys., 42, RG3001, doi:10.1029/2003RG000139.

Christy, J. R., R. W. Spencer, and W. D. Braswell, 2000: MSU tropospheric temperatures: Dataset construction and radiosonde comparisons. J. Atmos. Oceanic Technol., 17, 1153-1170.

Cogley, J. G., 2009: Geodetic and direct mass-balance measurements: Comparison and joint analysis. Ann. Glaciol., 50, 96-100.

Dee, D. P., and Coauthors, 2011: The ERA-Interim reanalysis: Configuration and performance of the data assimilation system. Quart. J. Roy. Meteor. Soc., 137, 553-597, doi:10.1002/qj.828.

Defourny, P., P. Mayaux, H. Herold, and S. Bontemps, 2012: Global land cover map validation experiences: Toward the characterization of uncertainty. Remote Sensing of Land Use and Land Cover: Principles and Applications, C. Giri, Ed., CRC Press, 207-223. 
Embury, O., C. J. Merchant, and G. K. Corlett, 2012: A reprocessing for climate of sea surface temperature from the along-track scanning radiometers: Initial validation, accounting for skin and diurnal variability. Remote Sens. Environ., 116, 62-78, doi:10.1016/j. rse.2011.02.028.

GCOS, 2010: Implementation plan for the global observing system for climate in support of the UNFCCC (2010 update). WMO GCOS Tech. Doc. GCOS-138 WMO-TD 1523, 23 pp.

_-, 2011: Systematic observation requirements for satellite-based products for climate, 2011 update. WMO GCOS Rep. 154, 127 pp.

Goldberg, M. D., 2007: Global Space-Based InterCalibration System (GSICS). Atmospheric and Environmental Remote Sensing Data Processing and Utilization III: Readiness for GEOSS, M. D. Goldberg et al., Eds., International Society for Optical Engineering (SPIE Proceedings, Vol. 6684), doi:10.1117/12.735246.

Jung, M., K. Henkel, M. Herold, and G. Churkina, 2006: Exploiting synergies of global land cover products for carbon cycle modelling. Remote Sens. Environ., 101, 534-553.

— and Coauthors, 2010: Recent decline in the global land evapotranspiration trend due to limited moisture supply. Nature, 467, 951-954.

Loeb, N. G., B. A. Wielicki, D. R. Doelling, G. L. Smith, D. F. Keyes, S. Kato, N. Manalo-Smith, and T. Wong, 2009: Toward optimal closure of the earth's topof-atmosphere radiation budget. J. Climate, 22, 748-766.
Mears, C. A., and F. J. Wentz, 2005: The effect of diurnal correction on satellite-derived lower tropospheric temperature. Science, 309, 1548-1551.

—- and - 2009: Construction of the Remote Sensing Systems V3.2 atmospheric temperature records from the MSU and AMSU microwave sounders. J. Atmos. Oceanic Technol., 26, 1040-1056.

Merchant, C. J., and Coauthors, 2012: A twenty-year independent record of sea surface temperature for climate from Along-Track Scanning Radiometers. J. Geophys. Res., 117, C12013, doi:10.1029/2012JC008400.

Paul, F., and Coauthors, 2013: On the accuracy of glacier outlines derived from remote sensing data. Ann. Glaciol., 54, 171-182.

Schneising, O., M. Buchwitz, M. Reuter, J. Heymann, H. Bovensmann, and J. P. Burrows, 2011: Longterm analysis of carbon dioxide and methane column-averaged mole fractions retrieved from SCIAMACHY. Atmos. Chem. Phys., 11, 2863-2880, doi:10.5194/acp-11-2863-2011.

Schulz, J., and Coauthors, 2009: Operational climate monitoring from space: The EUMETSAT Satellite Application Facility on Climate Monitoring (CMSAF). Atmos. Chem. Phys., 9, 1687-1709.

Solomon, S., D. Qin, M. Manning, M. Marquis, K. Averyt, M. M. B. Tignor, H. L. Miller Jr., and Z. Chen, Eds., 2007: Climate Change 2007: The Physical Science Basis. Cambridge University Press, $996 \mathrm{pp}$.

Stubenrauch, C., W. Rossow, and S. Kinne, 2012: Assessment of global cloud datasets from satellites. WCRP Rep. 23/2012, 175 pp.

Teixeira, J., D. Waliser, R. Ferraro, P. Gleckler, and G. Potter, 2011: Satellite observations for CMIP5 simulations. CLIVAR Exchanges, No. 165 (International CLIVAR Project Office, Southampton, United Kingdom, 46-47.

Trenberth, K. E., and Coauthors, 2013: Challenges of a sustained climate observing system. Climate Science for Serving Society: Research, Modelling and Prediction Priorities, G. R. Asrar and J. W. Hurrell, Eds., Springer, 13-50.

Williams, K. D., and M. J. Webb, 2009: A quantitative performance assessment of cloud regimes in climate models. Climate Dyn., 33, 141-157, doi:10.1007/s00382-008-0443-1. 